\title{
Bent Fiber Sensor for Preservative Detection in Milk
}

\author{
Omer Galip Saracoglu ${ }^{1, *}$ and Sekip Esat Hayber ${ }^{2}$ \\ 1 Department of Electrical and Electronic Engineering, Erciyes University, Kayseri 38039, Turkey \\ 2 Department of Electronic and Automation, Kaman Vocational College, Ahi Evran University, \\ Kirsehir 40300, Turkey; sehayber@ahievran.edu.tr \\ * Correspondence: saracog@erciyes.edu.tr; Tel.: +90-352-207-6666 \\ Academic Editor: Monica Florescu \\ Received: 24 October 2016; Accepted: 6 December 2016; Published: 9 December 2016
}

\begin{abstract}
A fiber optic sensor sensitive to refractive index changes of the outer region of the fiber cladding is presented. The sensor uses bent plastic optical fibers in different bending lengths to increase sensitivity. Measurements were made for low-fat milk, the refractive index of which is altered by some preservatives such as formaldehyde, hydrogen peroxide, and sodium carbonate. Concentrations of the preservatives in the milk were changed between $0 \%$ and $14.3 \%$ while the refractive indices occurred between 1.34550 and 1.35093 for the minimum $(0 \%)$ and maximum (14.286\%) concentrations of sodium carbonate, respectively. Due to bending-induced sensitivity, the sensor is able to detect refractive index changes less of than $0.4 \%$. The results show that there is excellent linearity between the concentration and normalized response of the sensor.
\end{abstract}

Keywords: bent fiber sensor; plastic optical fiber; concentration sensing; refractive index; milk

\section{Introduction}

Technological developments have made every area of our lives easier. One of the developments has taken place in the food industry because biosensor-based sensing technologies offer advantages in industrial processes and also in health and chemical ones [1]. In order to ensure safety and hence to increase food quality, the monitoring of contaminants and impurities such as preservatives in natural and daily foods has become a major interest [2-4]. Milk and products made from milk have a special place not only in our daily nutrition but also in our health. Because of the fact that they can carry harmful bacteria and microorganisms, they can spoil the products and make people sick. For this reason, many researchers have attempted to develop biosensors for detecting compositions and some contaminants such as enterotoxins, antibiotics, bacteria, aflatoxins [5-9] and monitoring some critical parameters such as the cutting time, $\mathrm{pH}$, temperature, and enzyme concentration [10-16] in milk and its products.

In order to produce quality and healthy products and to reduce infection risks, the purity of milk must be monitored at every stage of the process [17-19]. This is because researchers have used optical biosensors, especially by using light-matter interactions at both the molecular and bulk levels, for detection or monitoring of the critical parameters in milk and its products $[8,10,20]$. Optical biosensors utilize light-matter interactions at different levels and they have interesting features and abilities when compared to conventional electronic sensors such as immunity to electromagnetic interference, high sensitivity and selectivity, label-free detection, and ability for remote sensing [21,22].

There are some successful examples of fiber optic biosensors in open literature. Hao et al. used a fluorescence-based fiber optic probe to detect melamine in dairy samples such as liquid milk, yoghurt and baby formula milk [20]. They achieved detection with high sensitivities ranging from 12.62 to $284.18 \mu \mathrm{g} / \mathrm{L}$. Castillo et al. determined the milk cutting time with a fiber optic sensor by measuring backscattered light. They also monitored milk coagulation with the sensor [10]. The evanescent field created by the light passing through the fiber with total internal reflections 
can also be used for sensing purposes [20]. A plastic optical fiber (POF) biosensor was proposed by Wandermur et al. to detect Escherichia coli [8]. In such sensor designs, a bent or tapered sensing area offers better sensitivities [8,23-25]. In addition to fluorescent or absorption-based techniques, Jain and Sarma used the light-scattering technique to modulate UV-vis radiation for the online analysis of milk [4] and Liu et al., used near-infrared spectroscopy for similar purposes [5].

In this work, we designed and implemented a fiber optic sensor made of plastic optical fibers to detect some preservatives such as formaldehyde, hydrogen peroxide, and sodium carbonate. In order to ensure better interactions, we coiled the fibers with different turns. As a result, our simple design has been successfully able to detect the preservatives at concentrations of less than $5 \%$.

\section{Materials and Methods}

\subsection{Theory}

Power loss in optical fibers depending on bending is one of the signal attenuation mechanisms. In a multimode plastic optical fiber (POF), the light is guided by total internal reflections that occur in core-cladding interface of the fiber as shown in Figure 1a [26]. The guided light is tightly confined by the cladding at the interface while it passes through the fiber. However, a considerable part of the light leaks out the cladding as evanescent wave when the fiber is bent with a critical radius (Figure 1b). If the fiber is bent the smaller radius than the critical radius, the guiding condition in the fiber is degraded and a considerable part of the light escapes out the fiber (Figure 1c). While this signal loss can be considered as a drawback in optical fiber communication, it can be utilized as a useful tool for sensing purposes [24-30]. In this work, although there were successful samples of U-Shaped bent fiber sensors [31,32], the sensing area was formed by our designed coil shaped probe for the higher sensitivities.

The schematic in the Figure 1 is the main principle of the bent fiber sensors. The sensitivity can be adjusted depending on the bending radius and then, an amplitude modulation can be achieved by changing refractive index of the medium surrounding the bent area. Moreover, this principle can be used for concentration sensing because the refractive index of the surrounding medium is related to the concentration.

Our main goal in this work is to design a sensor system being capable of detecting the possible impurities in milk for every stages of the milk processing. So, we designed and implemented an optical sensor system to detect some contaminants such as formaldehyde, hydrogen peroxide, and sodium carbonate in low-fat commercial milk. The sensor uses POFs for both the light guiding medium and the sensor probe. Light source and photo detector of the sensor is a $660 \mathrm{~nm}$ LED (typical output power is $0.158 \mathrm{~mW}$ at $25^{\circ} \mathrm{C}$ ) and a photodiode-IC receiver (sensitivity is $0.135 \mathrm{~mW}$ at $25^{\circ} \mathrm{C}$ ), respectively (the transmitter and the receiver are from Avago Technologies, HFBR-1524Z and HFBR-2524Z, respectively [33]). The details of the sensor setup are shown in Figure 2. 

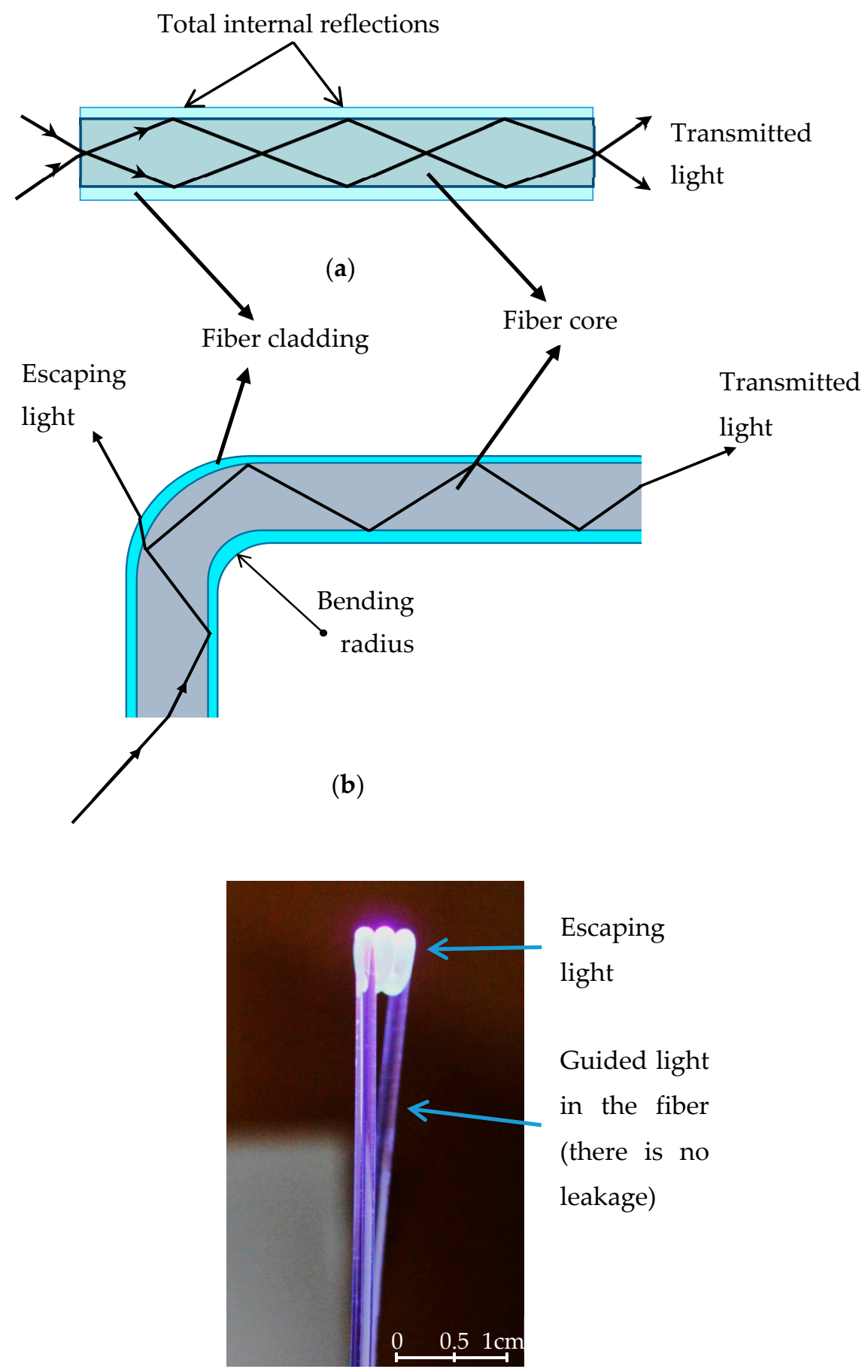

(c)

Figure 1. Light guiding in a multimode fiber. (a) Total internal reflection; $(\mathbf{b}, \mathbf{c})$ escaping light because of the bending. 


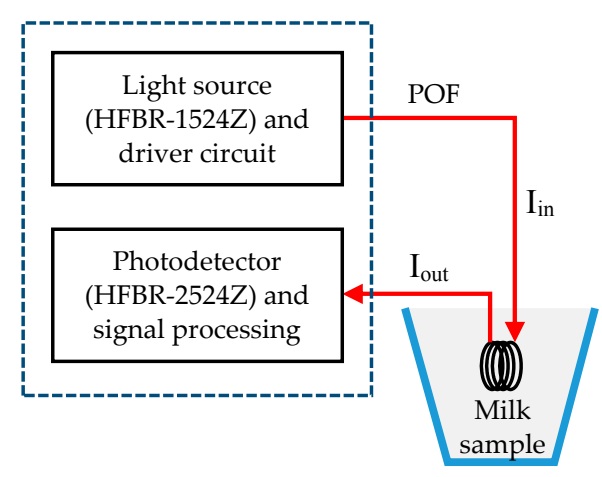

(a)

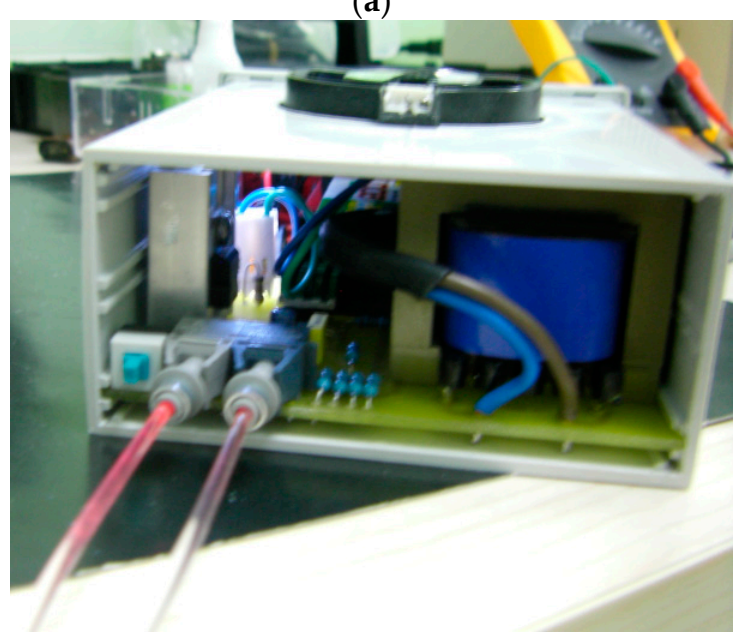

(c)

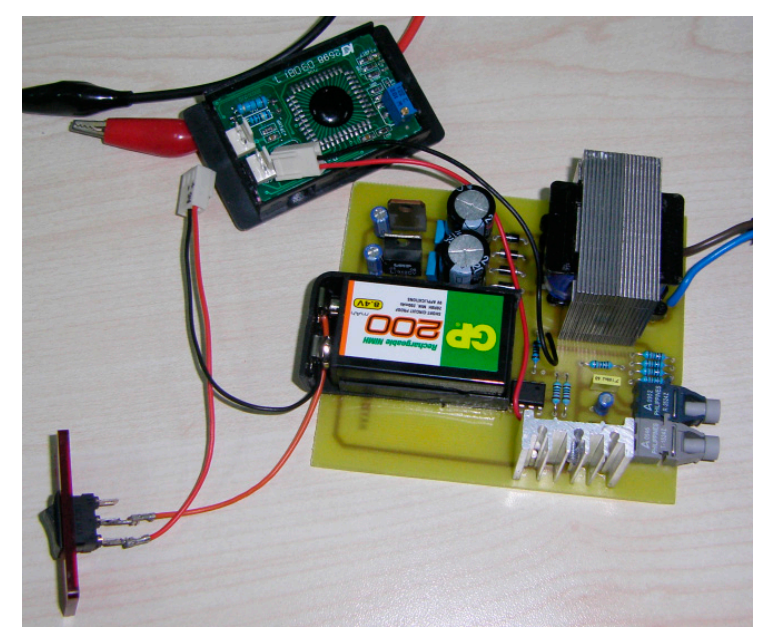

(b)

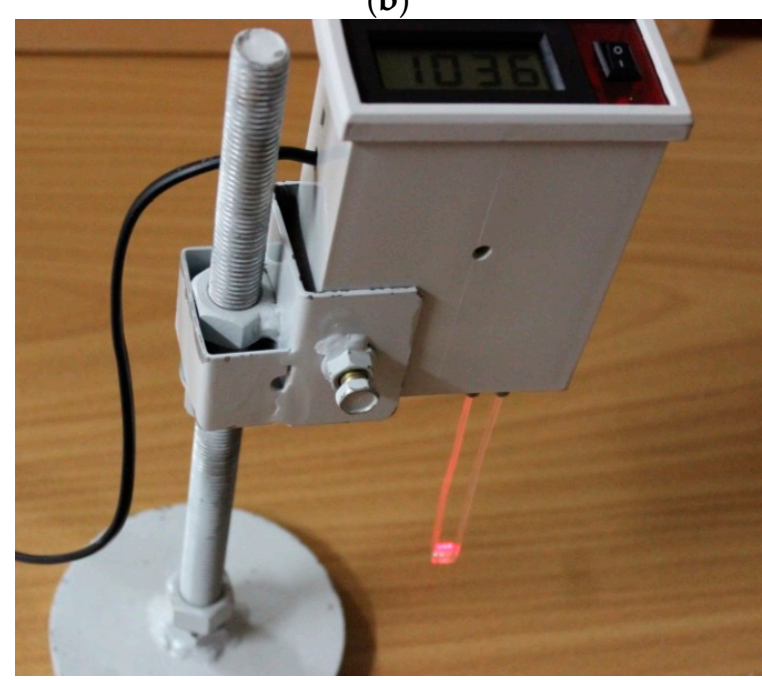

(d)

Figure 2. Sensor setup. (a) Schematic view of the setup; (b) printed circuit board placement; (c) inside view; (d) the final design ready for immersion into the milk sample.

\subsection{Sensing Probe}

Sensing probe is the most important part of the sensor system. We used three types of POFs having 1,2, and $3 \mathrm{~mm}$ diameters to prepare the probes. In order to shape the sensing area, we heated the fibers up to the softening temperature and then we coiled them on a mandrel of 3 mm diameter. The fabrication process is shown in Figure 3a. Thus, we obtained different coils and hence different interaction lengths with the surrounding medium. The number of probes prepared in this manner is 15 and they are given in Figure 3b.

Before the performance testing of the probes, we used a simple coding as given in Figure 4 . For example, P-132 code represents a POF having $1 \mathrm{~mm}$ diameter, wound on a $3 \mathrm{~mm}$ mandrel by two turns, respectively. 


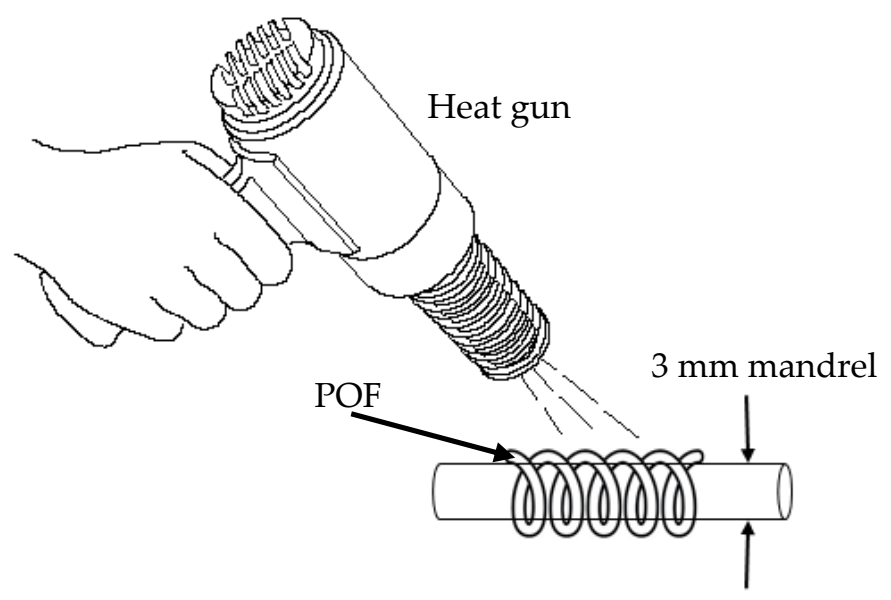

(a)

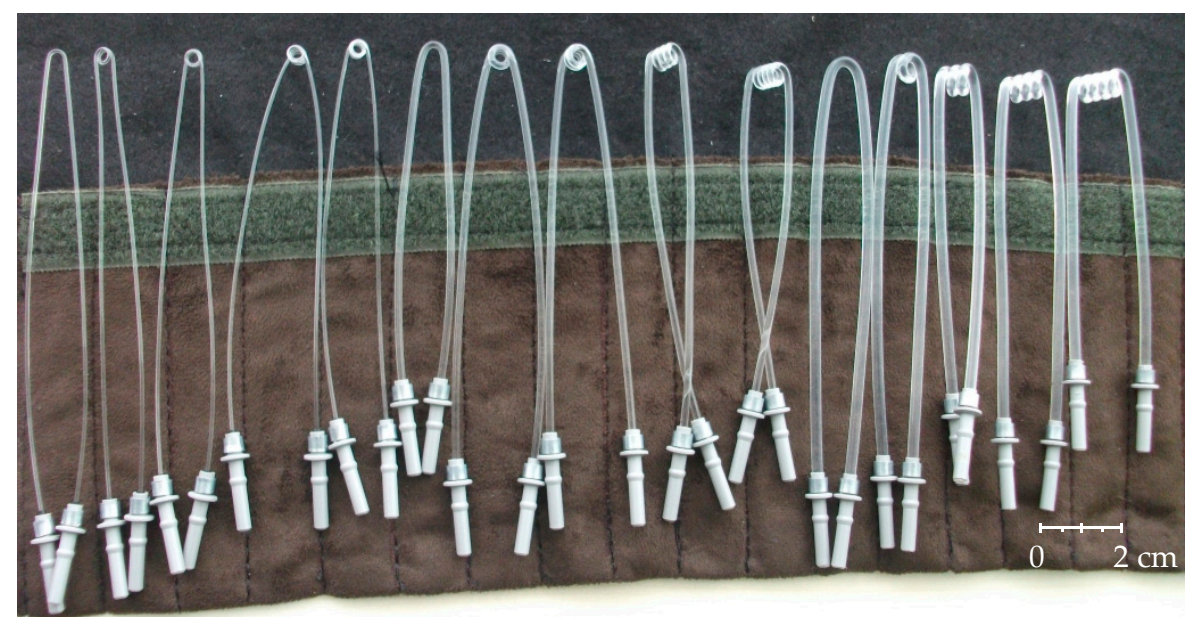

(b)

Figure 3. (a) Fabrication process of the probes; (b) Sensor probes.

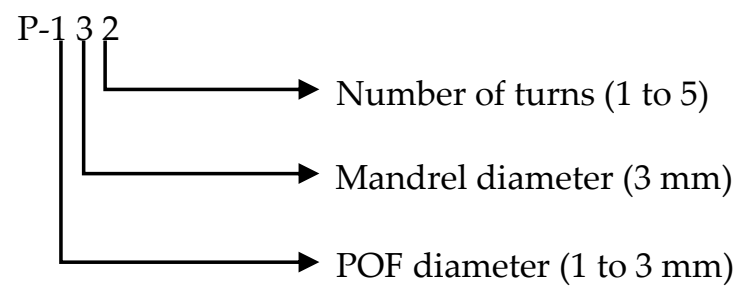

Figure 4. Explanation of the sensor probe coding used in this work.

\subsection{Probe Selection}

If we consider the designs from a simple point of view, the more interaction paths, the better sensitivity the sensor has. However, because of the escaping light, the increasing number of the turns limits the optical power reaching to the sensor output. On the other hand, another parameter known as normalized frequency of the fiber plays an important role on cladding power of the fiber [34]. The normalized frequency is given by [35]

$$
V=\frac{2 \pi}{\lambda} a(\mathrm{NA})
$$


where, $\lambda$ is the vacuum wavelength of the optic source, $a$ is the core radius, and NA is the numerical aperture of the fiber. Because of the fact that the wavelength and the NA are constants in our designs, the normalized frequency will vary with the core diameter. As a result, the cladding power fraction ( $\eta$ ) determining the sensitivity of the sensor design will inversely depend on the normalized frequency and hence the core diameter in accordance with [35],

$$
\eta=\frac{P_{\text {clad }}}{P_{\text {clad }}+P_{\text {core }}} \cong \frac{4}{3 V}
$$

In order to select the best candidates we performed some measurements by using the probes. During the measurements we recorded the readouts as $\mathrm{I}_{0}$ and $\mathrm{I}_{1}$ for which the probe is in air and in water, respectively. Since refractive index difference between the air $\left(\mathrm{n}_{0}=1.00\right)$ and water $\left(\mathrm{n}_{1}=1.33\right)$ gives sufficient outputs, we have simply used water. The results for determining the best candidates are given in Table 1.

Table 1. Determining the best candidates for the sensor probes.

\begin{tabular}{cccc}
\hline \multirow{2}{*}{ Probe } & \multicolumn{2}{c}{ Readouts (in Arbitrary Units) } & \multirow{2}{*}{$\mathbf{I}_{\mathbf{1}}-\mathbf{I}_{\mathbf{0}}$} \\
\cline { 2 - 3 } & $\mathbf{I}_{\mathbf{0}}$ (in Air) & $\mathbf{I}_{\mathbf{1}}$ (in Water) \\
\hline P-131 & 1000 & 1002 & 2 \\
P-132 & 1000 & 1003 & 3 \\
P-133 & 1000 & 1005 & 5 \\
P-134 & 1000 & 1006 & 6 \\
P-135 & 1003 & 1017 & 14 \\
P-231 & 1002 & 1052 & 50 \\
P-232 & $\mathbf{1 0 0 4}$ & $\mathbf{1 1 1 3}$ & $\mathbf{1 0 9}$ \\
P-233 & $\mathbf{1 0 0 5}$ & $\mathbf{1 2 5 8}$ & $\mathbf{2 5 3}$ \\
P-234 & 1022 & NOP 1 & - \\
P-235 & 1043 & NOP & - \\
P-331 & $\mathbf{1 0 1 2}$ & $\mathbf{1 3 0 3}$ & $\mathbf{2 9 1}$ \\
P-332 & 1048 & NOP & - \\
P-333 & 1090 & NOP & - \\
P-334 & 1298 & NOP & - \\
P-335 & 1401 & NOP & - \\
\hline \multicolumn{5}{c}{${ }^{1}$ NOP: No optical power at the output. } \\
\hline \multicolumn{3}{c}{}
\end{tabular}

NOP means in Table 1 that the optical power at the input of the receiver is less than $0.135 \mathrm{~mW}$ because of the losses in the sensing region. So, the receiver does not produce electrical power. After the measurements, we can consider the probes coded by P-232, P-233, and P-331 as the best candidates. Also we can see from Table 1 how POF diameters can affect the sensor readouts. By keeping constant the bending radius and the number of turns, the readouts against the POF diameter can be summarized as given in Table 2. One can expect that waveguide modes are tightly confined as POF diameter increases in contrast to Equation (2). However, bending radius will decrease when POF diameter increases since the mandrel has a constant radius.

In accordance with Equation (1), the sensor readouts can be tuned by wavelength of the optical source and by refractive index differences between the POF cladding and the surrounding medium. Since the wavelength of the source and the refractive index of the cladding are constant in this work, we used other parameters for sensor tuning.

Table 2. Effect of core diameters on sensitivity for the sensor probes.

\begin{tabular}{cccc}
\hline \multirow{2}{*}{ Probe } & \multicolumn{2}{c}{ Readouts (in Arbitrary Units) } & \multirow{2}{*}{$\mathbf{I}_{\mathbf{1}}-\mathbf{I}_{\mathbf{0}}$} \\
\cline { 2 - 3 } & $\mathbf{I}_{\mathbf{0}}$ (in Air) & $\mathbf{I}_{\mathbf{1}}$ (in Water) & \\
\hline P-131 & 1000 & 1002 & 2 \\
P-231 & 1002 & 1052 & 50 \\
P-331 & 1012 & 1303 & 291 \\
\hline
\end{tabular}




\section{Results and Discussion}

Some preservatives such as formaldehyde, hydrogen peroxide, and sodium carbonate, etc., are used to prevent acidity in milk [36]. In this work, we prepared different solutions by using commercial low-fat $(0.1 \%)$ milk in which these preservatives were added in different concentrations. The refractive index of the milk increases up to 1.35093 with the preservatives added, while the initial value is 1.34550 . It is well known that the refractive indices of the samples are highly dependent on the temperature. So we conducted the experiments between the temperatures of 24 and $26{ }^{\circ} \mathrm{C}$ in order to prevent index fluctuations in the samples. The measurements for the different concentrations of the preservatives are given in Tables 3-6. The tables show the readouts of P-233 because it has better sensitivities. We did not use P-331 because it has a 3-mm-diameter POF which creates immeasurable losses due to over-bending. This situation points out, in our designs, that bent-dependent power losses will increase as the POF diameters get larger since the mandrel diameter is constant at $3 \mathrm{~mm}$. A detailed discussion of the losses due to bending can be found in Reference [37]. Note that in all the sensor readouts in the tables, $\mathrm{I}_{0}$ and $\mathrm{I}_{1}$ are in arbitrary units; the readouts get higher when the refractive index of the surrounding medium increases. Also note that we used commercially available preservatives to adjust the refractive indices. For example, hydrogen peroxide-39 means that the commercial packaging contains $39 \mathrm{~mL}$ pure hydrogen peroxide and $61 \mathrm{~mL}$ distilled water. This simple explanation is valid for the other preservatives.

Table 3. Sensor readouts with probe P-233 for hydrogen peroxide-39.

\begin{tabular}{ccccc}
\hline $\begin{array}{c}\text { Hydrogen Peroxide-39 } \\
\text { Concentration (\%) }\end{array}$ & Refractive Index & $\mathbf{I}_{\mathbf{0}}$ (in Air) & $\mathbf{I}_{\mathbf{1}}$ (in Milk) & $\mathbf{I}_{\mathbf{1}}-\mathbf{I}_{\mathbf{0}}$ \\
\hline 0.00000 & 1.34550 & 1008 & 1310 & 302 \\
1.63934 & 1.34566 & 1008 & 1310 & 302 \\
3.22581 & 1.34581 & 1008 & 1312 & 304 \\
4.76190 & 1.34595 & 1008 & 1313 & 305 \\
6.25000 & 1.34609 & 1008 & 1314 & 306 \\
7.69231 & 1.34623 & 1008 & 1315 & 307 \\
9.09091 & 1.34636 & 1008 & 1316 & 308 \\
10.44776 & 1.34649 & 1008 & 1319 & 311 \\
11.76471 & 1.34662 & 1008 & 1319 & 311 \\
13.04348 & 1.34674 & 1008 & 1321 & 313 \\
14.28571 & 1.34686 & 1008 & 1322 & 314 \\
\hline
\end{tabular}

Table 4. Sensor readouts with probe P-233 for sodium carbonate-12.5.

\begin{tabular}{ccccc}
\hline $\begin{array}{c}\text { Sodium Carbonate-12.5 } \\
\text { Concentration (\%) }\end{array}$ & Refractive Index & $\mathbf{I}_{\mathbf{0}}$ (in Air) & $\mathbf{I}_{\mathbf{1}}$ (in Milk) & $\mathbf{I}_{\mathbf{1}}-\mathbf{I}_{\mathbf{0}}$ \\
\hline 0.00000 & 1.34550 & 1008 & 1310 & 302 \\
1.63934 & 1.34571 & 1008 & 1314 & 306 \\
3.22581 & 1.34591 & 1008 & 1318 & 310 \\
4.76190 & 1.34611 & 1008 & 1322 & 314 \\
6.25000 & 1.34630 & 1008 & 1324 & 316 \\
7.69231 & 1.34648 & 1008 & 1326 & 318 \\
9.09091 & 1.34666 & 1008 & 1328 & 320 \\
10.44776 & 1.34684 & 1008 & 1330 & 322 \\
11.76471 & 1.34701 & 1008 & 1330 & 322 \\
13.04348 & 1.34717 & 1008 & 1331 & 323 \\
14.28571 & 1.34733 & 1008 & 1332 & 324 \\
\hline
\end{tabular}


Table 5. Sensor readouts with probe P-233 for formaldehyde-37.

\begin{tabular}{ccccc}
\hline $\begin{array}{c}\text { Formaldehyde-37 } \\
\text { Concentration (\%) }\end{array}$ & Refractive Index & $\mathbf{I}_{\mathbf{0}}$ (in Air) & $\mathbf{I}_{\mathbf{1}}$ (in Milk) & $\mathbf{I}_{\mathbf{1}}-\mathbf{I}_{\mathbf{0}}$ \\
\hline 0.00000 & 1.34550 & 1008 & 1310 & 302 \\
1.63934 & 1.34598 & 1008 & 1312 & 304 \\
3.22581 & 1.34644 & 1008 & 1318 & 310 \\
4.76190 & 1.34689 & 1008 & 1320 & 312 \\
6.25000 & 1.34732 & 1008 & 1323 & 315 \\
7.69231 & 1.34774 & 1008 & 1329 & 321 \\
9.09091 & 1.34815 & 1008 & 1334 & 326 \\
10.44776 & 1.34854 & 1008 & 1336 & 328 \\
11.76471 & 1.34892 & 1008 & 1339 & 331 \\
13.04348 & 1.34930 & 1008 & 1343 & 335 \\
14.28571 & 1.34966 & 1008 & 1346 & 338 \\
\hline
\end{tabular}

Table 6. Sensor readouts with probe P-233 for sodium carbonate-25.

\begin{tabular}{ccccc}
\hline $\begin{array}{c}\text { Sodium Carbonate-25 } \\
\text { Concentration (\%) }\end{array}$ & Refractive Index & $\mathbf{I}_{\mathbf{0}}$ (in Air) & $\mathbf{I}_{\mathbf{1}}$ (in Milk) & $\mathbf{I}_{\mathbf{1}}-\mathbf{I}_{\mathbf{0}}$ \\
\hline 0.00000 & 1.34550 & 1008 & 1310 & 302 \\
1.63934 & 1.34612 & 1008 & 1314 & 306 \\
3.22581 & 1.34673 & 1008 & 1324 & 316 \\
4.76190 & 1.34731 & 1008 & 1330 & 322 \\
6.25000 & 1.34788 & 1008 & 1336 & 328 \\
7.69231 & 1.34842 & 1008 & 1344 & 336 \\
9.09091 & 1.34895 & 1008 & 1350 & 342 \\
10.44776 & 1.34947 & 1008 & 1355 & 347 \\
11.76471 & 1.34997 & 1008 & 1360 & 352 \\
13.04348 & 1.35046 & 1008 & 1366 & 358 \\
14.28571 & 1.35093 & 1008 & 1373 & 365 \\
\hline
\end{tabular}

As can be seen from the tables, the sensor probe P-233 can respond to very small changes in the concentration of as much as $1.24 \%$, while the average is $1.43 \%$. The sensitivity in terms of the refractive index difference has very interesting results. The maximum difference in the refractive index is $1.34612-1.34550=6.2 \times 10^{-4}$ (in Table 6 , rows 2 and 1 ) while the minimum value is $1.34686-1.34674=1.2 \times 10^{-4}$ (in Table 3, rows 11 and 10). These numerical evaluations show that the sensor probe is able to detect $1.5 \%$ changes in concentrations or $5.0 \times 10^{-4}$ changes in refractive indices, roughly.

As another performance evaluation, we used a normalized response $(R)$ as given below:

$$
R=\frac{x_{i}-x_{\min }}{x_{\max }-x_{\min }}
$$

where $x_{i}$ refers to any of the $\mathrm{I}_{0}-\mathrm{I}_{1}$ values in Table 6 while $x_{\max }$ and $x_{\min }$ are the maximum and minimum values of the column, respectively. Then we depicted the response of P-233 for sodium carbonate-25 solutions in terms of $R$ graphically in Figure 5. It can clearly be seen that there is an excellent linearity between the concentration and normalized response. In order to test the repeatability of the responses, we made an additional measurement. The errors for the measurements are under $3 \%$. These results were shown with error bars in Figure 5. 


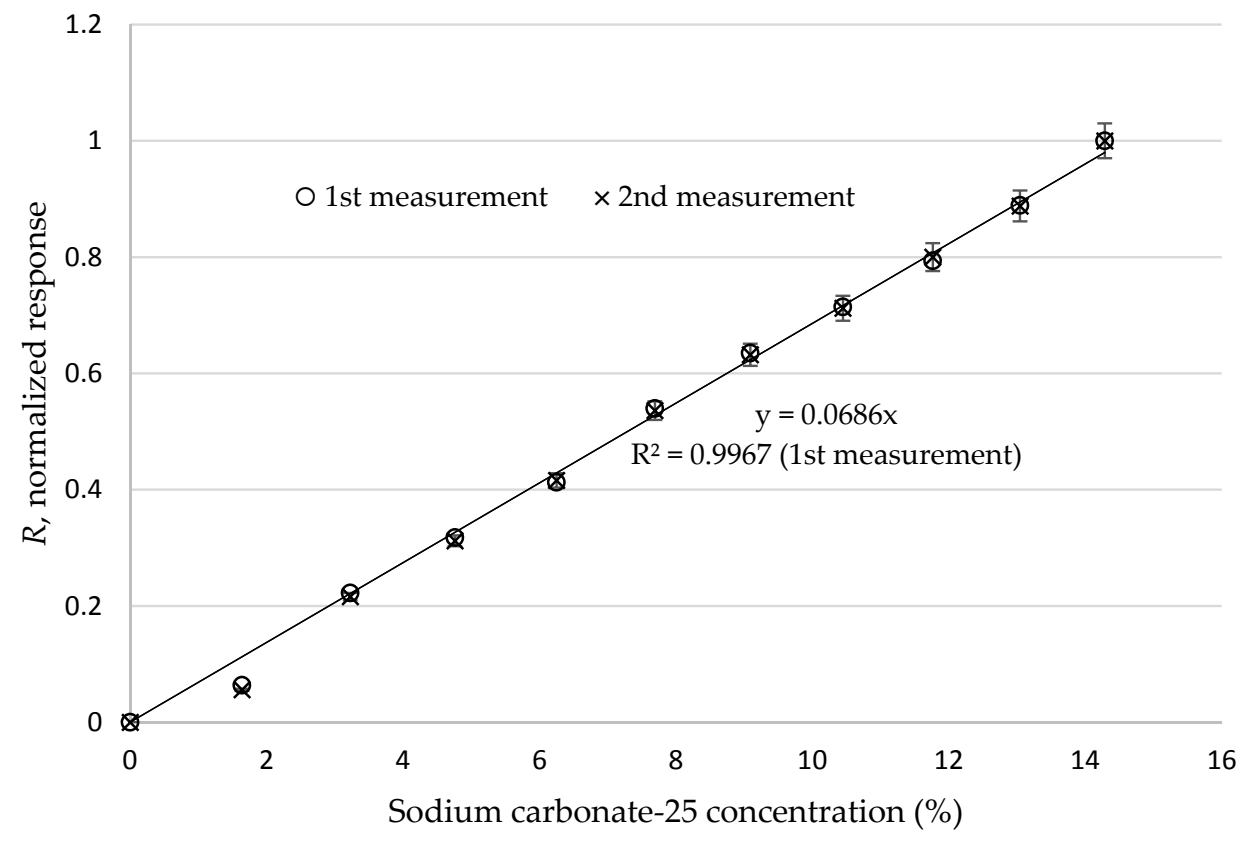

Figure 5. Normalized response of P-233 against percentage concentration (error bars represent less than $3 \%$ error for the measurements).

The sensor response of probe P-233 in terms of the refractive index change is shown in Figure 6. It can be clearly seen from the figure that there is an excellent linear relationship between the refractive indices and the sensor responses.

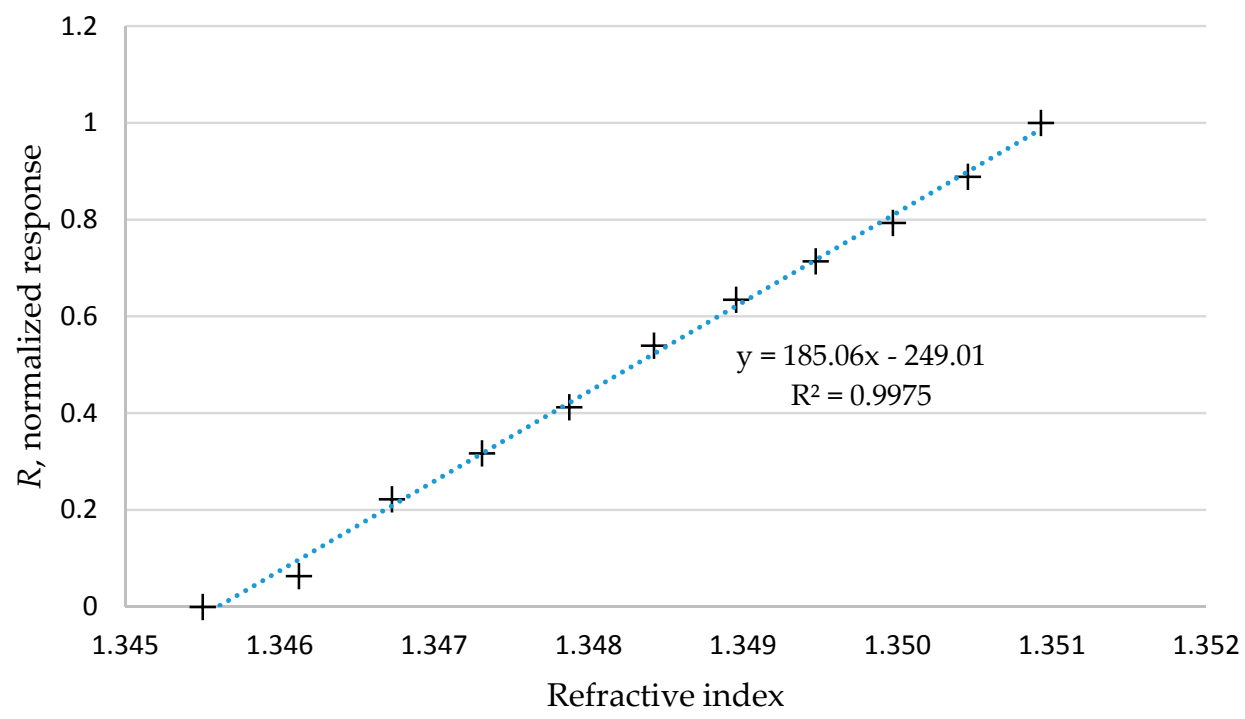

Figure 6. Normalized response of P-233 against refractive index change.

\section{Conclusions}

A fiber optic sensor made by bent plastic optical fibers has been presented. The sensor is sensitive to the refractive index changes determined by the concentrations of the medium surrounding the sensing area. The surrounding medium is low-fat milk, the refractive index of which is altered by some preservatives, i.e., formaldehyde, hydrogen peroxide, and sodium carbonate. By adding the preservatives, the resulting refractive indices are changed between 1.34550 and 1.35093 for the minimum $(0 \%)$ and maximum $(14.3 \%)$ concentrations of the sodium carbonate-25, respectively. 
The average change in the concentration is about $1.43 \%$. As a result, we obtained excellent linearity between the concentration and normalized response of the sensor.

It is concluded that the sensor presented in this work can be adopted in liquid food processes to monitor for any target parameter subject to refractive index changes.

Acknowledgments: This work was supported by the Research Fund of the Ahi Evran University. Project number FBA-10-03.

Author Contributions: Omer Galip Saracoglu provided the main idea, conceived and designed the experiments, and wrote the paper for this study; Sekip Esat Hayber performed the experiments and analyzed the data.

Conflicts of Interest: The authors declare no conflict of interest.

\section{References}

1. Florescu, M.; Hu, W. Evaluation of Si nanowire as biosensing device. J. Optoelectron. Adv. Mater. 2015, 17, 1092-1098.

2. Van der Spiegel, M.; Sterrenburg, P.; Haasnoot, W.; Van Der Fels-Klerx, H.J. Towards a decision support system for control of multiple food safety hazards in raw milk production. Trends Food Sci. Technol. 2013, 34, 137-145. [CrossRef]

3. De Souza, G.C.S.; da Silva, P.A.B.; Leotério, D.M.D.S.; Paim, A.P.S.; Lavorante, A.F. A multicommuted flow system for fast screening/sequential spectrophotometric determination of dichromate, salicylic acid, hydrogen peroxide and starch in milk samples. Food Control 2014, 46, 127-135. [CrossRef]

4. Jain, P.; Sarma, S.E. Light scattering and transmission measurement using digital imaging for online analysis of constituents in milk. In Proceedings of the Optical Measurement Systems for Industrial Inspection IX, Munich, Germany, 22-25 June 2015.

5. Liu, J.; Ji, Z.; Tian, M. Near-infrared spectroscopy (NIRS) analysis of major components of milk and the development of analysis instrument. In Proceedings of the Multispectral, Hyperspectral, and Ultraspectral Remote Sensing Technology, Techniques and Applications V, Beijing, China, 13-16 October 2014.

6. Homola, J.; Dostalek, J.; Chen, S.; Rasooly, A.; Jiang, S.; Yee, S.S. Spectral surface plasmon resonance biosensor for detection of staphylococcal enterotoxin B in milk. Int. J. Food Microbiol. 2002, 75, 61-69. [CrossRef]

7. Adrian, J.; Pasche, S.; Diserens, J.M.; Sánchez-Baeza, F.; Gao, H.; Marco, M.P.; Voirin, G. Waveguide interrogated optical immunosensor (WIOS) for detection of sulfonamide antibiotics in milk. Biosens. Bioelectron. 2009, 24, 3340-3346. [CrossRef] [PubMed]

8. Wandermur, G.; Rodrigues, D.; Allil, R.; Queiroz, V.; Peixoto, R.; Werneck, M.; Miguel, M. Plastic optical fiber-based biosensor platform for rapid cell detection. Biosens. Bioelectron. 2014, 54, 661-666. [CrossRef] [PubMed]

9. $\mathrm{Xu}, \mathrm{X}$.; Liu, X.; Li, Y.; Ying, Y. A simple and rapid optical biosensor for detection of aflatoxin B1 based on competitive dispersion of gold nanorods. Biosens. Bioelectron. 2013, 47, 361-367. [CrossRef] [PubMed]

10. Castillo, M.; González, R.; Payne, F.A.; Laencina, J.; López, M.B. Optical monitoring of milk coagulation and inline cutting time prediction in Murcian al Vino cheese. Appl. Eng. Agric. 2005, 21, 465-471. [CrossRef]

11. Abdelgawad, A.R.; Guamis, B.; Castillo, M. Using a fiber optic sensor for cutting time prediction in cheese manufacture from a mixture of cow, sheep and goat milk. J. Food Eng. 2014, 125, 157-168. [CrossRef]

12. Arango, O.; Trujillo, A.J.; Castillo, M. Predicting coagulation and syneresis parameters of milk gels when inulin is added as fat substitute using infrared light backscatter. J. Food Eng. 2015, 157, 63-69. [CrossRef]

13. Revilla, I.; González-Martín, I.; Hernández-Hierro, J.M.; Vivar-Quintana, A.; González-Pérez, C.; Lurueña-Martínez, M.A. Texture evaluation in cheeses by NIRS technology employing a fibre-optic probe. J. Food Eng. 2009, 92, 24-28. [CrossRef]

14. González-Martín, I.; Hernández-Hierro, J.M.; Vivar-Quintana, A.; Revilla, I.; González-Pérez, C. The application of near infrared spectroscopy technology and a remote reflectance fibre-optic probe for the determination of peptides in cheeses (cow's, ewe's and goat's) with different ripening times. Food Chem. 2009, 114, 1564-1569. [CrossRef]

15. Ranieri, M.L.; Ivy, R.A.; Mitchell, W.R.; Call, E.; Masiello, S.N.; Wiedmann, M.; Boor, K.J. Real-time PCR detection of Paenibacillus spp. in raw milk to predict shelf life performance of pasteurized fluid milk products. Appl. Environ. Microbiol. 2012, 78, 5855-5863. [CrossRef] [PubMed] 
16. Balabin, R.M.; Smirnov, S.V. Melamine detection by mid-and near-infrared (MIR/NIR) spectroscopy: A quick and sensitive method for dairy products analysis including liquid milk, infant formula, and milk powder. Talanta 2011, 85, 562-568. [CrossRef] [PubMed]

17. Borecki, M.; Niemiec, T.; Korwin-Pawlowski, M.L.; Kuczyńska, B.; Doroz, P.; Urbańska, K.; Szmidt, M.; Szmidt, J. Optoelectronic and photonic sensors of mastitis in cow milk. In Proceedings of the Electron Technology Conference, Ryn, Poland, 16-20 April 2013.

18. Kaşıkçı, G.; Çetin, Ö.; Bingöl, E.B.; Gündüz, M.C. Relations between electrical conductivity, somatic cell count, California mastitis test and some quality parameters in the diagnosis of subclinical mastitis in dairy cows. Turk. J. Vet. Anim. Sci. 2012, 36, 49-55.

19. Ozhikandathil, J.; Badilescu, S.; Packirisamy, M. Gold nanostructure-integrated silica-on-silicon waveguide for the detection of antibiotics in milk and milk products. In Proceedings of the Photonics North 2012, Montreal, QC, Canada, 6-8 June 2012.

20. Hao, X.J.; Zhou, X.H.; Zhang, Y.; Liu, L.H.; Long, F.; Song, L.; Shi, H.C. Melamine detection in dairy products by using a reusable evanescent wave fiber-optic biosensor. Sens. Actuat. B Chem. 2014, 204, 682-687. [CrossRef]

21. Narsaiah, K.; Jha, S.N.; Bhardwaj, R.; Sharma, R.; Kumar, R. Optical biosensors for food quality and safety assurance-A review. J. Food Sci. Technol. 2012, 49, 383-406. [CrossRef] [PubMed]

22. Abdelhaseib, M.U.; Singh, A.K.; Bailey, M.; Singh, M.; El-Khateib, T.; Bhunia, A.K. Fiber optic and light scattering sensors: Complimentary approaches to rapid detection of Salmonella enterica in food samples. Food Control 2016, 61, 135-145. [CrossRef]

23. Preejith, P.V.; Lim, C.S.; Kishen, A.; John, M.S.; Asundi, A. Total protein measurement using a fiber-optic evanescent wave-based biosensor. Biotechnol. Lett. 2003, 25, 105-110. [CrossRef] [PubMed]

24. Da Silveira, C.R.; Costa, J.C.; RoccoGiraldi, M.T.M.; Jorge, P.; López Barbero, A.P.; Germano, S.B. Bent optical fiber taper for refractive index measurements with tunable sensitivity. Microw. Opt. Technol. Lett. 2015, 57, 921-924. [CrossRef]

25. Zawawi, M.A.; O'Keeffe, S.; Lewis, E. Plastic Optical Fibre Sensor for Spine Bending Monitoring with Power Fluctuation Compensation. Sensors 2013, 13, 14466-14483. [CrossRef] [PubMed]

26. Borecki, M. Clad radiation rating in optical polymer fibres. Proc. SPIE 2006, 6159. [CrossRef]

27. Borecki, M. Light behaviour in polymer optical fibre bend-A new analysis method. Opt. Appl. 2013, 33, 191-204.

28. Borecki, M. Intelligent fiber optic sensor for estimating the concentration of a mixture-design and working principle. Sensors 2007, 7, 384-399. [CrossRef]

29. Borecki, M.; Kruszewski, J. Skew radiation in optical fiber: The proposal of share measure. In Proceedings of the Optical Fibers: Applications, Warsaw, Poland, 31 August-2 September 2005.

30. Fang, Y.-L.; Wang, C.-T.; Chiang, C.-C. A Small U-Shaped Bending-Induced Interference Optical Fiber Sensor for the Measurement of Glucose Solutions. Sensors 2016, 16, 1460. [CrossRef] [PubMed]

31. Gupta, B.D.; Dodeja, H.; Tomar, A.K. Fibre-optic evanescent field absorption sensor based on a U-shaped probe. Opt. Quant. Electron. 1996, 28, 1629-1639. [CrossRef]

32. Gupta, B.D.; Sharma, N.K. Fabrication and characterization of U-shaped fiber-optic pH probes. Sens. Actuat. B Chem. 2002, 82, 89-93. [CrossRef]

33. HFBR-0500Z Series-Avago Technologies. Available online: http://www.avagotech.com/docs/AV021501EN (accessed on 8 December 2016).

34. Saraçoglu, Ö.G.; Ozsoy, S. Simple equation to estimate the output power of an evanescent field absorption-based fiber sensor. Opt. Eng. 2002, 41, 598-600.

35. Gloge, D. Weakly guiding fibers. Appl. Opt. 1971, 10, 2252-2258. [CrossRef] [PubMed]

36. Cerdán, J.F.; Peris-Tortajada, M.; Puchades, R.; Maquieira, A. Automation of the determination of hydrogen peroxide, dichromate, formaldehyde and bicarbonate in milk by flow injection analysis. Fresenius J. Anal. Chem. 1992, 344, 123-127. [CrossRef]

37. Snyder, A.W.; Love, J. Optical Waveguide Theory; Kluwer Academic Publishers: London, UK, 2000; pp. 179-188.

(C) 2016 by the authors; licensee MDPI, Basel, Switzerland. This article is an open access article distributed under the terms and conditions of the Creative Commons Attribution (CC-BY) license (http://creativecommons.org/licenses/by/4.0/). 